DOI: 10.20472/IAC.2017.032.037

\title{
PRIYAM SINGH
}

Galgotias University, India

\section{MANY INDIAN LITERATURES: AN ILLUSTRATION OF THE ANCIENT YET STEADILY GROWING COSMOPOLITAN}

\begin{abstract}
:
India is a land of contradictions because the co-existence of multiplicities has been the norm here. This is not to say that there is consonance in the many differences that persist but that at some level or the other, there is acceptance and nothing can be completely shunned. To put it in a magic realistic understanding of Marquez and apt words by Arundhati Roy for India, "India lives in several centuries at the same time. Somehow we manage to progress and regress simultaneously." In that spirit, this paper intends to chart through some specific examples of the literary texts from India, the path of to and fro between which India will look like an enchanting exploration but in actuality show narratives steeped in its politics, law and culture. Namely they will include, 'Cilappatikaram' by Adigal which is an epic with a female protagonist, 'Raag Darbari' by Srilal Shukla which is a satirical rendering of a post independence Indian village, a comparative effort between India's foremost epic 'Mahabharata' and its modern day telling by Dr. Shashi Tharoor called 'The Great Indian Novel', 'A Fine Balance' by Rohinton Mistry which entails the threatening politics within a democratic nation and finally 'Ghachar Ghochar', originally written in Kannada by Vivek Shanbhag and recently translated into English, a masterpiece touching to the realistic core, the effects money and success can have on different people while hearkening to 'Financial Expert' written by R.K. Narayan. These examples in their content and context coming from different states of India, written in several genres and languages and various time periods in the last hundred years or so is illustrative of the melting pot that India has been. Why is the level of tolerance in this country debatable but never dismissed? The idea of this paper presentation is to depict India's cosmopolitan literature and that despite the bans of many books in India, the country does not altogether support the muffling of voices, evident in its culture of writing over the years and also in recent Supreme Court judgments'.
\end{abstract}

\section{Keywords:}

Indian literature, cosmopolitan, culture of writing, languages, female protagonist, voices 
The title of the paper is an amalgamation of various specific adjectives with which Indian literatures may be addressed and has been. The reason why it is not just Indian literature but Many Indian literature's' is rather obvious. As the paper hopes to trace through examples of few novels, the story each endeavour tells is a telling very different from another. Besides, they come written in various languages which get translated into others for readers within the same nation! Thus the representation of the heterogeneity of its various forms of writing is what the title depicts. In fact, it has been simplified from the several varied nomenclatures with which it began to be identified initially, namely, the Anglo-Indian literature, Indo-Anglican literature, Indo-English literature or Indian contribution to English Literature. In the recent past, while all writings within India are not in English language, the works are being translated into English and has consolidated itself under the name of Indian English Writing. There is no fixed context or range of contexts that the authors aspire to. These disparate subjects upon which novels have been penned makes it difficult for them to be classified.

The other part of the topic of the paper hints towards a worldview of shared values that are espoused by an intellectual group that writers belong to. Whatever be the main subject, their interest is in investing themselves to universal values that almost every liberal country in this world wants to follow; that of being secular and egalitarian, economically independent, fraternal etc. Even through the literature it produces, India is seen to have been self- reflective and self-reprimanding upon these lines. According to Robert Spencer in the essay Cosmopolitan Literature and Post Colonial Criticism, "If we wish to spell out what it is that literature can give us," "then we ought to pay heed to the description by the French philosopher of Hermeneutics, Paul Ricoeur, of how the interpretative process helps reformulate us into beings capable of undertaking selfcriticism". This principle guides Spencer in his insistence that postcolonial literature teaches its readers "self-scrutiny", "self-criticism", and "self-reflection". Further, Spenser desires to depict that cosmopolitan literature, not constrained by the boundaries of any one particular cultural belief in fact holds the active position of changing the world besides describing it. This very approach is Marxist if we recall the famous quote by Marx- "the philosophers have so far interpreted the world in several ways. The point however, is to change it". C.L.R. James is believed to be of the opinion that colonialism is not dead and 
will not be unless replaced by a positive doctrine and this for Spencer is the "global civil society" established by cosmopolitanism replete with revolutionary possibilities. However, there is a warning in this case about being too "celebratory" as this transformation may appear in the form of neo-imperial homogenization carried out in cosmopolitanism's name.

So, while the paper describes Indian literatures as cosmopolitan it is aware of the strangleholds to avoid while not being limited by any one canon. Some ideas purported by philosophers like Thich Nhat Hanh also hold true with respect to being open to worldly wise values and that is the concept of "Interbeing", a way of living life in relation to others. Paul Gilroy warns of the acceptance of discriminating ideas as a result of generalizations around race in its name. Kwame Anthony Appiah extends an interesting understanding that democracy is a pre-requisite for cosmopolitanism to make strides cloaked as colonization from which the people then fight back.

Thus there is a need to streamline the sundry descriptions of cosmopolitanism capable of creating confusion in accordance with the view held generally through the length of the paper, where some discernments can be agreed upon. Cosmopolitanism is the openness to ideas, cultures, translated texts, sparsely explored subject matter and treating it as a 'cosmos' in itself which constructs and deconstructs the world within it. The paper talks of it in the realm of literature and therefore the diversity of narrative techniques and several literary genres are at play and are also played with in the novels being discussed. The novels content includes the currently relevant discussions as well as the contemporaneity of age old wisdom, it contests the stalwarts or legendary and cares to glance upon the minions, it offers the scope of change to discover that the centre cannot hold, it tries to unearth optimism but realizes realism. In all, the comprehension is that ideas along with people who propagate them are rotating around an axis symbolized by the most powerful. There is no fixed status and history is 'plural and provisional' allowing for circularity of events of which we see but one vision and at other times with different perspective see alternative images.

The novels that will be discussed in the paper include 'Cilappatikaram' by llango Adigal in 1946, which is a text in verse. Originally written in Tamil, it not just borrows the regional language of India but its literary tradition of Akam and Puram poetry imbibed within the 
scale and narrative of an epic which is then challenged as a form because it belies some of the characteristics and has been called an anti-epic by some scholars. It has a female protagonist who acquires justice for herself and that in itself is a distinctive feature. In 1952 came out the Financial Expert by R.K.Narayan that will be referred to briefly to situate the most contemporary novel Ghachar Ghochar(2016, in English) in the genre that talks of relation of finance with Indian people. The latter text is an intriguing tale of a family who suddenly comes into money and although they earn profit from the business henceforth, they lose control of their lives and relationship with each other. Reading this novella especially gives good stance of cosmopolitanism in Indian literature because like the story in which the male head of the family Appa says, "wealth should not strike suddenly like a visitation but instead grow gradually like a tree", cosmopolitanism in India's context or any developing country cannot be suddenly imbibed in practice just because of its merits. It needs to penetrate the psyche of the native people and that means the elite and the deprived people, alike. This would lend a good understanding of the next novel and its character of Dhritrashtra, a roman a clef for Pandit Jawaharlal Nehru in the 'The Great Indian Novel'(1989) by Dr.Shashi Tharoor. Imposed cosmopolitanism can be seen as resulting in disaster as the setting up of dams and industries did nothing for the $80 \%$ rural population of India who were not against it but more concerned with their basic needs of food, clothing and shelter. Dhritrashtra is a blind Kaurava king in the Indian epic Mahabharata and his characterization upon Nehru is done on the basis of his blind idealism about ideas, such as described above. 'The Great Indian Novel' is one that works closely upon inscribing mythology of Mahabharata into history of India pre and post independence up to the time of the declaration of Emergency. This parallel of two 'texts' are found to be starkly similar in its analogy and present a very realistic world of 'interbeing', of surviving in the world in relation with one another. Finally, the paper will also explore Rohinton Mistry's 'A Fine Balance' which would be the epitome to discuss the depiction of evading the dangers of living in a multi polar world where discriminatory attitudes can sometimes take centre stage and continue to be accepted as a matter of normalization due to tradition but there is equal possibility of breaking the mould because the contemporaneous time was sheltered by constitutional democracy and equality. How much of that was in actual practice remains to be investigated but one 
thing is for sure that once Dina employs the untouchable tailors Omprakash and Ishwar and rents a room to the student Maneck and they begin to stay together, a semblance of balance in their lives acquired from interdependence is attained. They are do away with prejudices and a woman employer living with three strange men, making for an otherwise unlikely possibility in Indian society creates a truly momentary cosmopolitan.

There are some common features found in all the stories. The stories have been a see saw between good and bad fortune. Whether it be the happily wedded Kovalam and Kannaki in Cillapatikaram whose life is diverted through Kovalam's distraction towards Matavi or Omprakash and Ishwar who suffer atrocities as lower caste Dalits to rising above their professional trades of cattle skinning to learning the craft of tailors, the Indian Independence movement and Mahabharata is well know action for its escalations and violent endings and finally in Ghachar Ghochar a modestly earning yet content family to becoming well to do but losing all calm. That fate play a role although not the most overwhelming is something the Indian population believes in to a large extent. What this shows through all this is a critique of move towards individualism and material yearnings. Indian moral compass is a complex web which has been modified over time but the literatures or its writers have been constant critics of short cuts to wealth and of evading familial duty. Why it is convoluted is that although family values are an important part and in fact Indians have always believed in Vasudev Kutumbakam which means that the world is my family, they are also obsessed with power and undeniable and constant rifts and feuds exist within the families. This gives us a portrayal that is not ideal but realistic and true. The concept of the family is not limited to a connection through birth but by alliances with likeminded people as in A Fine Balance where Dina resents Nusswan, her brother but after initial hesitation makes the tailors and the student her family. In Mahabharata and the allegorical tale spun by Dr.Tharoor in The Great Indian Novel, people with same political interests and aims to emancipate the nation are depicted as one unhappy family. Karna in Mahabharata or Mohammad Ali Karna in the allegorical novel are both part of the same Kaurava family but in each they are castigated and find hope and peace in different homes. Also Shalya, Madri's brother who is mother of Nakul-Sahdeva is tricked into a feast by the Kauravas and out of a duty to grant them a wish he has to fight the Kurukshetra war on the side of Kauravas instead of the Pandavas. Kovalam and Matavi 
have a more fruitful conjugal life and a daughter is also born to them outside wedlock while the chaste duty abiding wife Kannaki never enjoys that bliss and at end snatches away her breast over the city of Maturai upon its uselessness on Kovalam's death. In Raag Darbari, the patriarch of the family in Shivpalganj is subject to physical abuse by the younger son. Thus, the concept of family is let loose by fateful situations, by choice,without choice but due to the need, intervention of death or mere opportunist behaviour. In Ghachar Ghochar, Anita is not able to fit in with the narrator nor is the narrator's sister Malti able to continue with her husband and in the core family itself, a disjunct is felt since the days they became rich. If we just hearken back to one of the famous lines on families, all happy families are alike, each unhappy family is unhappy in its own way, all these families depict just that and in a world which aspires to an idealistic structure are woven and unwoven into different family threads.

While these common mechanisms of family are not ideal, the State as a whole works towards being a Welfare State and when that is not possible, it leads to disaster. In Cilappatikaram, there are various symbols of the king which when found distorted are signs of his failure of duty. The bent umbrella, the ringing of the bell by citizens calling the king etc, in Mahabharata and in its allegorical novel lead to the finishing of the whole Kaurava Clan and here the disrobing of democracy by calling Emergency in the presence of fighters who had staked their life for freedom. Again, in 'A Fine Balance', the trains run on time( In India, that is a rarity), there is beautification of the city by crushing the slums, there are family planning programmes which actually castrate many men in order to gain government incentives, the attempt at that point is to run the government smoothly but the Prime Minister has actually evaded Constitutional Mechanism and court judgements to declare Emergency. In Raag Darbari by Srilal Shukla, voting is something that needs to be exercised but who is voted for and who wins is decided by voting booth capturers. Thus an outside façade of a Welfare State and its mechanisms are present and this narrative is important to prove to the world over that we are a cosmopolitan state but the discrepancies are always there. However, to not run hollow the argument that India wishes for that State, an example of Indian Press printing blank pages garnered international attention during the Emergency in 1975. Thus, as Appiah had said, the 
existence of democracy is necessary for cosmopolitan ideas to take wings and then, the other elements of the State-its people fight back.

There are many other instances when these novels have mocked at cosmopolitan ideals. The nationalist movement and the disappointment suffered after its victory is kept at rerun in several novels. The worst of course was the Partition. The system of courts which are the platforms for fair trials are also not shown much faith in, because of the time it takes. There is a lot of backlog. They have been shown disregard in satires like Raag Darbari where it is said that the theory of reincarnation had been invented in civil courts so that the plaintiff and defendant do not regret that their cases were left undecided. The Great Indian Novel criticizes the freedom fighters for betraying the very freedom they fought for. The cataclysm that is forms the beginning of life after independence and even as it was being granted. Instead of the famous last words of Gandhiji, Gangadatta in The Great Indian Novel dies saying I have failed. Tharoor writes at some point that the era of Mahaguru was over and everyone who was in favour of partition had actually defeated Gandhiji. Kannaki absolves her husband Kovalam of blame and proves the judicial system of Maturai inefficient by exposing the discrepancy and lack of investigation and thought put into the matter. In Mistry's novel, the lack of autonomous control that police have and are directed by a PM herself flouting rules of a democracy which her father though an idealist had helped carve out of British hands. The lack of freedom of expression, the poverty on the streets, were all a failure of the dream and that is why she was in reality at the brink of losing elections. In fact, much to a shock of the first time reader, there is a Beggarmaster in this novel who is more successful in taking care of the poor across the city. He puts different poor people in charge of separate areas for begging and then collects his revenue which he also uses to feed his employees.

Apart from these themes, the style of writing is very important to note. It owes patronage to none and unlike the present Government which has been involved in banning a few books in the country; all these books were never put off shelves, although disapproved of. Khuswant Singh, writer and Journalist had said of Dr.Tharoor's book, that it would be taken off shelves in one week but contrary to expectations this retelling of an epic in present political scenarios(1989) which made potshots at religious sources( called the Rig Veda, the Rigged Veda) and legendary leaders was not banned. Raag Darbari was 
a poignant critique of bureaucratic system and inefficiency of election commission in fact went on for several reprints. Cilapattikaram published in 1946, had such sensual poetry written allegedly by a Jain Monk was never a matter of controversy in the prudish times of the nation.

All these books being discussed have used a plethora of writing techniques to grasp its audience by its intelligent and insightful writing with relevant themes. The style cannot make any one realize that it belongs to Indian English writings. It is even more commendable because books like Raag Darbari, Cilapattikaran have been translated texts but read with just as much relish and the grammar translation from the original Tamil text has been scrutinized minutely to much applause. The Great Indian Novel is a pun on the Indian epic Maha=great and Bharat=Indian but the author has refused to take claim of such greatness. Besides, while it refuses the Indian epic, it cannot refute the references made to 'The Great American novel', as he has named several chapters $f$ the book on names of books of American Authors such as 'The Son Also Rises', etc. It makes use of pun, irony, itihaasa, kavya, mythology. Epic and History are not treated with much seriousness and satire is used to present them. Caricaturing of several freedom fighters including Gangadatta(Gandhiji) as more concerned with experiments in celibacy and cow protection and then eventually, losing control of the Kaurava Party. Very clever rendering of the five Pandus as agencies of the State- Bhishma as Army, Arjun as Press, foreign service and bureaucracy.

Tharoor also makes a continuous re-assessment of the present scenario of politics and it leads to Indian history being transformed into characters from mythology and the mythical story of India is retold as History of Indian Independence. At the beginning of the novel, the narrator Vyasa says that history is full of savage ironies and I am just telling the truth that I know. This analysis directly references Louis Montrose's theory about New Historicism where he says, the textuality of history and the historicity of texts.

Raag Darbari is a strong uprooting of the romanticism of a village. By the end of the novel, Rangnath the nephew of Vaidyaji who had gone to recuperate was running away and being chased by the coarse, political, power hungry atmosphere, a reality trying to catch up with him. The failure of the education system disappoints him even more because he discovers that the intellect of his is of no use in such a crass setting. He uses brilliant 
satire to depict the inevitable presence of filth at bus stands by calling it part of Programmed Planning and the natural partner of this was regular presence of pigs which religiously scattered the rubbish. There is no sentimental morality in the families; they are far from being 'sanskari'. (full of respectable values) Corruption, nepotism and the failure of nationalistic ideals are seen when Vaidyaji wins the election at gunpoint and muscle power is also very important. Hypernormalised is a word coined by Adam Curtis BBC Journalist, during the fall of the Soviet Union when a society aware of the fact that things are not normal, have acclimatized to the ethical absurdity of the situation. The feelings that Rangnath suffers are not of hypernormalism but the village Shivpalganj can probably fall in that category. In the numbness that follows, right at the beginning Ranganath reaches the railway station 2 hours late because he is sure the train will be late by that much time as a rountine. He was left behind because the train was half an hour faster.

Cilappatikaram is also special for its writing styles as it conforms to Puram and Akam poetry but most of all because it has a female protagonist as against the norm of male heroes. As against a man winning war, Kannaki uses her virtues of karpu (a quality which is not inherent but developed, chastity) and anaku(female sexuality) to deliver the justice she desired over her wrongly accused and killed husband. She does not get subsumed into the ground but apotheosized into a goddess. This has been called by Dr.Kinshuk Majumdar as an anti epic. Often what is found absent in epics of valour is genuine human empathy and upon finding her husband's dead body Kannaki calls out in a tone of human empathy, a quality she has yearned for more than ever in Kovalam's absence instead of the quick revenge that resulted in her husband's death. More than anything, what the world needs against all the talks of separatism and factionalism is love. Karma is another unavoidable important aspect of any individual's life. Kovalam according to the epic has some penalty to pay for deeds in his past life and it was his fate that led him more than his infatuation with Matavi, on a path away from his wife. Similarly, there is a theory of Karma transfer. The company of a person in the longer phase of life will create some effect on his or her life. Kannaki's presence makes the saintly Kavunti so involved that she dies of hard penance to be followed soon after by tragedy for Kannaki and Kovalam's death. When the king of Maturai kills himself for having wrongly indicted Kovalam, it is 
followed by death of his wife as well. Matavi as a result of being abandoned, becomes a saint for penance or else she was a wonderful dancer and singer.

Ghachar Ghochar speaks of a world where human beings lose their agency to money. At one point before this family after the family becomes well off, the narrator says that in the beginning if one spent money, it meant that he was taking away from another and the head of the family- Appa, used to be important. Today he has lost importance and money has gained that control which he wielded earlier. Money has given the luxury to engage elsewhere and the significance of the personhood is lost out to the family. The only time they combine forces is when they are using their clout to extract the jewellery Malti had been given in marriage and her marriage itself has become less important than that material object. Thus this novel is questioning in the world of sufficient means the redundancy of the value system of an Indian family. At least, when the novel 'The Financial Expert' had come out, it had a swami like figure who was selling happiness. At least, the pursuit or quest was qualitative. This gives the understanding that basic needs are important for human happiness but beyond a point, these materials if not paid attention to gain control over a living human being. As for the stylistic technique of this novella, one of the critics has remarked "language real enough for semi-literate and devoid of literary grace". A cosmopolitan writing also gains access to the semi-literate if that is to be believed and as one literate myself, have no complains about the veracity and insights that this tale offers.

Thus, all novels take up ideas from different parts of the world along with the telling of its local story and performs entertainment as well critique in forms of writing familiar as well as original and thus consolidates its position in a cosmopolitan world.

\section{References}

Majumdar, Dr.Kinshuk.2015. The Cilapattikaram:Tale of an Anklet by llanko Atikal. Institute of Lifelong Learing, University of Delhi

Saffire,Paula.Review of Parasarathy's translation of Cilappatikaram by Ilanko Atikal 1995.Digital Commons@Butler University.9-1995

Miller, Eric. Feb,2007. Kannagi:Global System of Justice 2007. National Seminar on Silappathikaram at Government College,Chittur, Kerala. 
Macphail, Richard Donald. May,1988. Justice,foreknowledge and Fate in the Cilapatikaram. Macmaster University.

Kumari,Lalitha. 2007. A Study of Factions in the Novels of Shashi Tharoor. The Mythopoetics of History in The Great Indian Novel. Chapter II. Pg 103-160.

Guruprasad, S.Y.2015. Satire in Shahi Tharoor's 'The Great Indian Novel'.Vol II,Issue X.International Journal of English Language, Literature and Humanities.

Ayoub,Shaifta. July,2014. Raag Darbari as a Rural Dystopia. European Academic Research.

Batra, Jagdish. Emerging Trends in the $21^{\text {st }}$ Century Indian English Novels

Naik, M.K. 1987. Studies in Indian English Literature. Sterling Publications. 